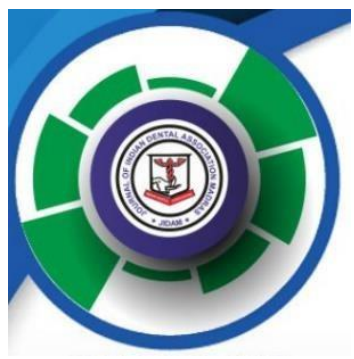

\title{
REHABILITATION OF FRACTURED CENTRAL INCISOR WITH RICHMOND CROWN- A CASE REPORT
}

\author{
Dr.Yusuf Shaikh, Dr. Babita Yeshwante, Dr. Nazish Baig, Dr. Kalyani Deshmukh \\ Department of Prosthodontics, CSMSS dental college Aurangabad, Maharashtra, India
}

DOI: 10.37841/jidam_2021_V8_I2_06

Address for correspondence:

Dr.Yusuf Shaikh,

Post Graduate Student

Kedy tower, Nagpada Mumbai central,

India.

Email id: yusufshaikh36@gmail.com

Received: 10.03.2021 First Published: 29.05.2021

Accepted: 25.05.2021

Published: 27.06.2021

\begin{abstract}
Rehabilitation of badly broken endodontically treated teeth is a common problem in restorative dentistry. Tooth with less remaining crown height is indicated for post and core followed by crown to restore normal anatomy, function and esthetics. Patients having reduced interocclusal clearance and are most difficult to manage. Richmond crown is a feasible approach for such cases that can be performed with less incisal clearance as it accommodates post, core and crown thickness. In this case report, diagnosis and treatment planning for a case with fracture of maxillary central incisor along with fabrication technique of Richmond crown has been discussed.
\end{abstract}

KEYWORDS: Fractured tooth, Richmond crown, Dowel and Core 


\section{INTRODUCTION:}

Challenges have increased for restorative dentistry, with the advent of scientific endodontic therapy in the 1950 's. Teeth are now successfully treated with predictable endodontic therapy that were extracted without hesitation; a satisfactory restorative solution was necessary.

In 1879 A.D, C.M Richmond resolved the retention problem encountered between porcelain crowns and posts commonly made of wood by fusing porcelain to a platinum post (Richmond crown, Fig.1). The Richmond crown is "a post-retained crown made for an endodontically treated tooth that uses a porcelain facing" (GPT9). ${ }^{1}$ It is customized castable post and crown system as both are single unit and casted together. Cast metal restorations are easier to make with the aid of posts for retention and lasting service. Whenever possible the metal can be camouflaged by veneering with tooth-colored restorations. ${ }^{2,3,4,5}$ The Richmond crown is indicated in cases with grossly decayed single tooth with very much reduced crown height and with increased deep bite and decreased overjet. ${ }^{6}$

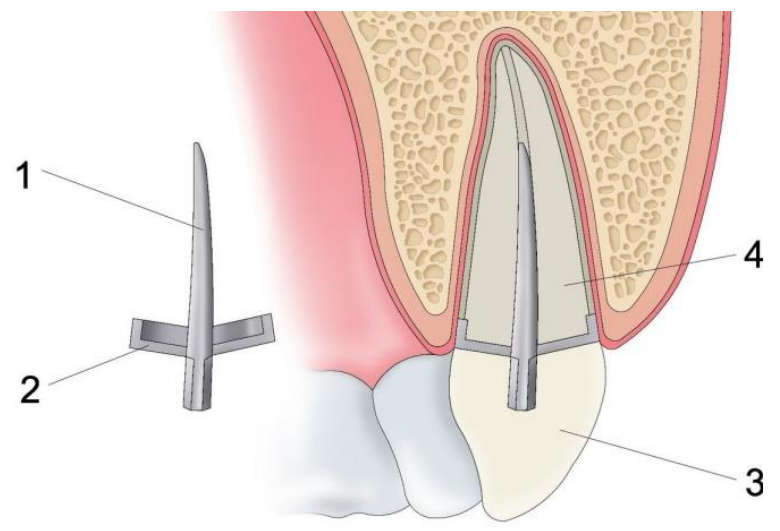

Fig 1: 1-post, 2-cap, 3-crown, 4-root

This case report describes a patient with fractured central incisor treated with a simple and minimally invasive technique of restoration with Richmond crown.

\section{MATERIALS AND METHODOLOGY:}

A 37-year-old patient reported to the Department of Prosthodontics with the complaint of bad aesthetics due to fractured upper right front teeth. After detailed history taking and examination of patient, it was revealed that the patient underwent trauma 1 year back and his maxillary right central incisor had got fractured and was root canal treated but crown was not given (Fig.2). On examination of oral cavity it was found that tooth 21 was fractured (Fig.3). Radiographic evaluation revealed single canal, with root canal treatment done and horizontal crown fracture with the right central incisor. No periapical changes were noted. Thus, there was no need of re-root canal treatment. Layered zirconia Richmond crown was planned as it can be a better option instead of prefabricated posts because of major loss of tooth structure. The treatment plan was explained to patient.

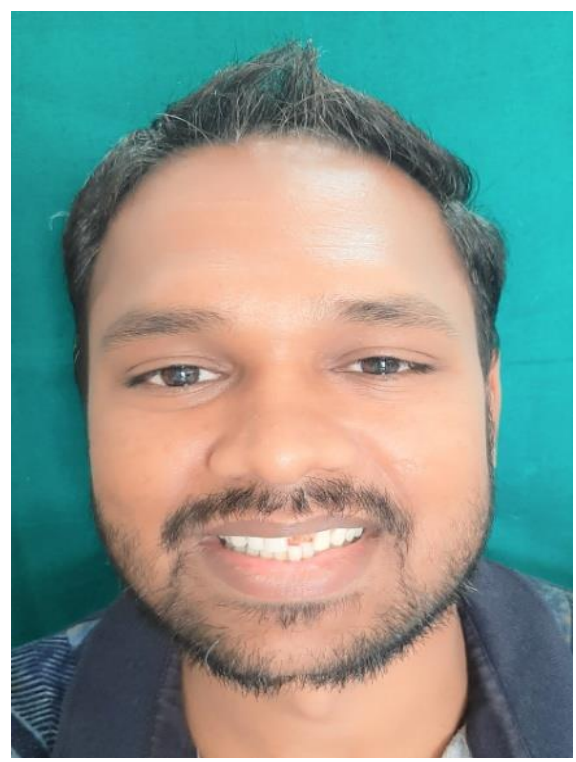

Fig 2: Pre-operative extra-oral photograph

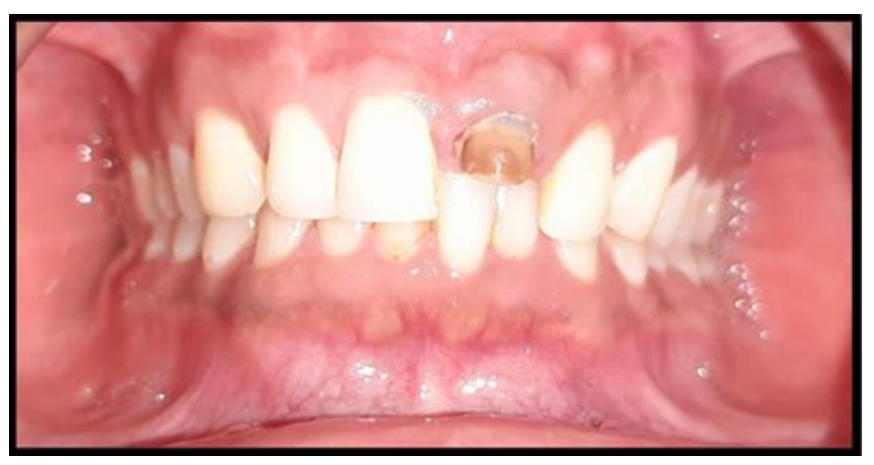

Fig 3: Pre-operative intra-oral photograph

\section{POST SPACE PREPARATION:}

It is important to preserve 3 to $5 \mathrm{~mm}$ of apical gutta percha to maintain the apical seal (proportionist approach). Thus gutta percha was removed from canal with Gates Glidden drill (size 1 to 4), without disturbing the apical seal and maintaining $4 \mathrm{~mm}$ of gutta percha in the apex. The post should be surrounded by a minimum of $1 \mathrm{~mm}$ of sound dentin (Preservationist approach \& conservationist approach). Post space preparation was done with paeso reamer drill up to size \#04. Intra-oral periapical radiograph was taken to check for adequate post-space preparation (Fig.4). 
Yusuf et al: Rehabilitation of fractured Central Incisor with Richmond Crown

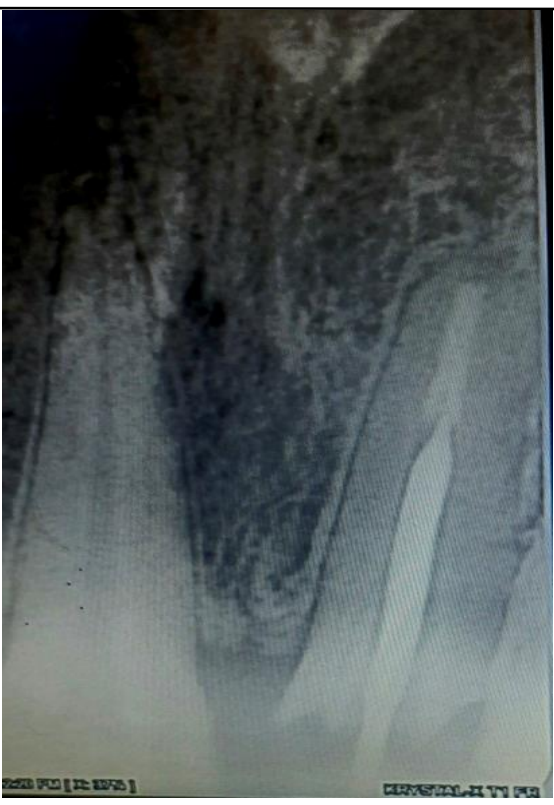

Fig 4: Intra-oral periapical radiograph showing post space preparation

\section{CROWN STRUCTURE PREPARATION:}

Crown structure was prepared circumferentially for zirconia crown with shoulder finish line. Incisal edge was then given with crown ferrule effect for better retention.

\section{IMPRESSION:}

For making final impression, the canal was coated with light body impression material (Impressiv) and then a small piece of orthodontic wire, coated with light body was placed in the canal. Later light body was injected around the prepared tooth, putty impression material (Perfit) was loaded in stock tray and final impression was made (Fig.5). The impression was examined for defects in recording of post space.

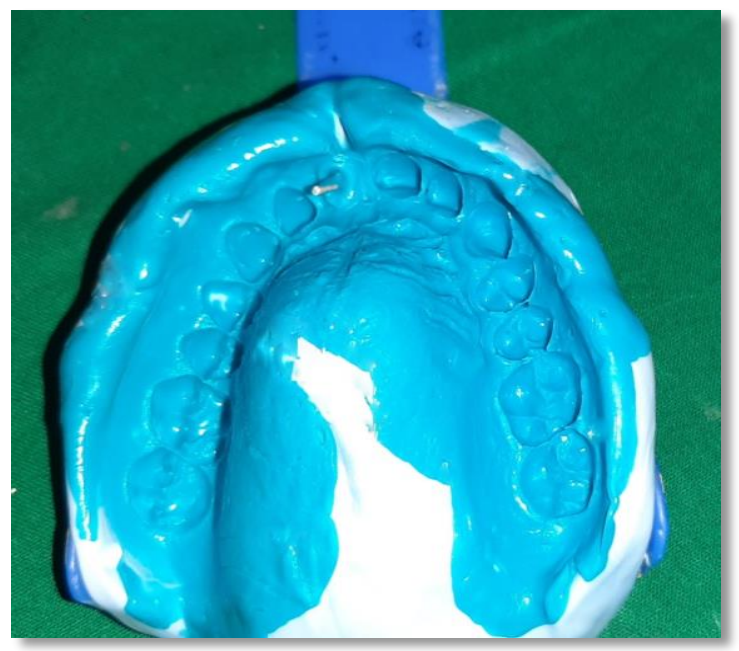

Fig 5: Final impression with impression of post space
FABRICATION AND CEMENTATION OF RICHMOND CROWN:

It was then poured with die stone and wax pattern was fabricated for Richmond crown and scanned for fabrication of zirconia coping (Fig.6). Coping try-in was done before layering (Fig.7). The restoration was sandblasted with aluminum oxide after try-in of final prosthesis. Cementation was done with automatic self-adhesive resin cement (RelyX). Small amount of cement was discarded onto the mix-pad to ensure a perfect mix. Cement was applied on the post surface and lentulo spiral was used to spin the cement into the canal. Filling the canal with cement before seating the post will avoid air entrapment and ensure a dense uniform cement lute. Light cured for 20 seconds per surface. Excess cement was removed (Fig.8).

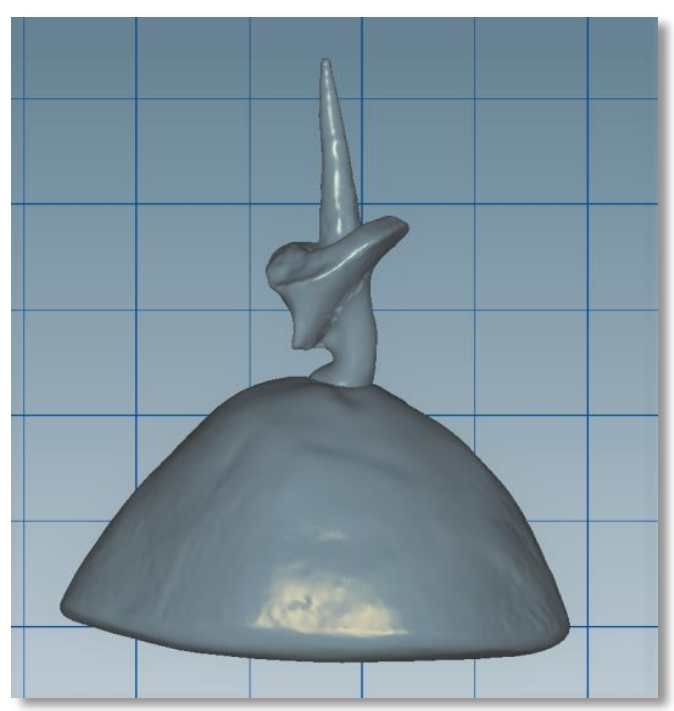

Fig 6: Wax pattern was fabricated and scanned for fabrication of zirconia coping

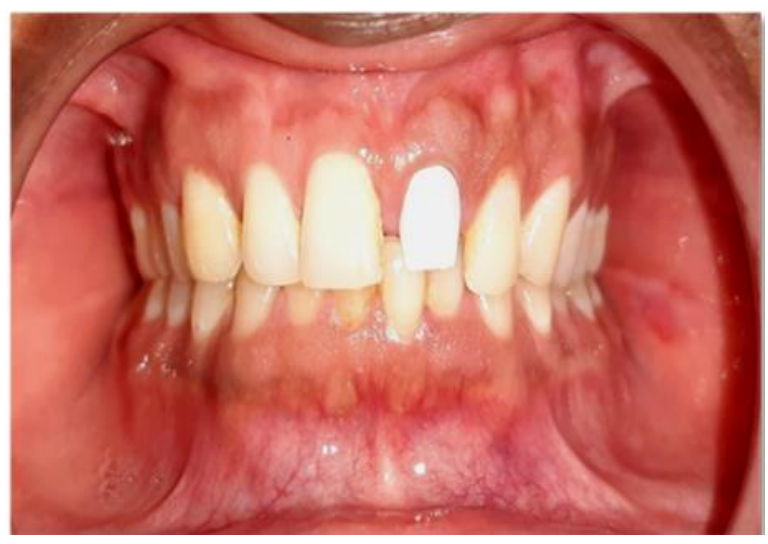

Fig 7: Zirconia coping try-in 
Yusuf et al: Rehabilitation of fractured Central Incisor with Richmond Crown

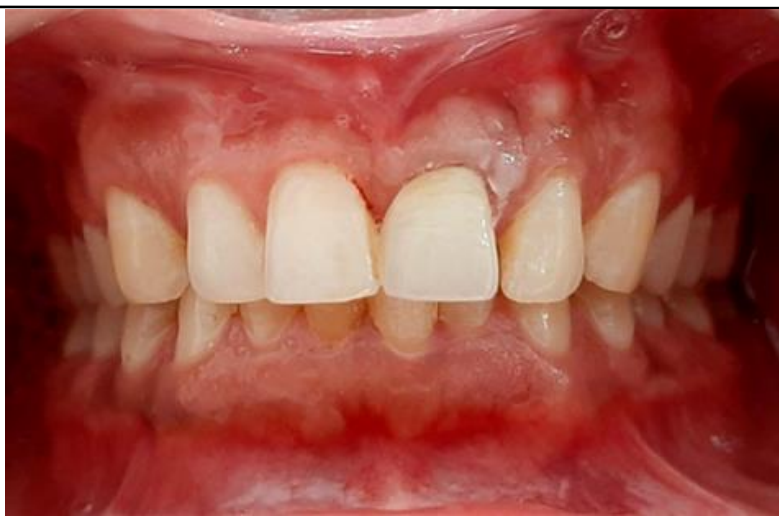

Fig 8: Cementation of richmond crown done with resin cement

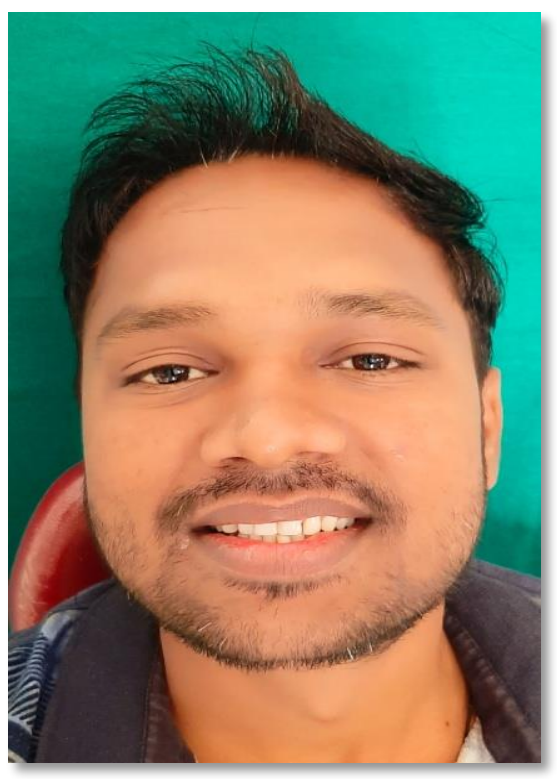

Fig 9: Post-operative extra-oral photograph

\section{DISCUSSION:}

Pierre Fauchard described the use of "tenons,", as early as 1728, which were metal posts screwed into the roots of teeth to retain bridges.7 In the late 19th century, the "Richmond crown," a single-piece post-retained crown with a porcelain facing, was engineered to function as a bridge retainer. Design include casting of post and crown coping as single unit over which ceramic is fired and cemented inside canal and over prepared crown structure having same path of insertion. ${ }^{2,3,4,5}$ For providing antirotational effect, ferrule collar was incorporated. Also creating ferrule effect, increases mechanical resistance and retention. Major limitation of this design is excessive preparation in making two different axis parallel which results in weakening of tooth and also this design increases stress at post apex causing root fracture. Indications for Richmond crown are grossly decayed or badly broken single tooth where remaining crown height is very less and incases with steep incisal guidance (deep bite and very less overjet). (Fig.9).
The advantages of this design are custom fitting to the root configuration, high strength, availability of considerable space for ceramic firing and incisal clearance, little or no stress at cervical margin, eliminates cement layer between core and crown so reduces chances of cement failure. However certain disadvantages include; that it requires multiple appointments, it is time consuming, high cost, high modulus of elasticity than dentin (10 times greater than natural dentin $)^{7}$, less retentive than parallel-sided posts, and acts as a wedge during occlusal load transfer and if the ceramic part fractures, then it is difficult to retrieve which can finally lead to tooth fracture. ${ }^{8}$

The all-zirconium posts are quite rigid, with a modulus of elasticity higher than stainless steel (Meyerberg KH et al; 1995 and Rovatti L 1998). ${ }^{9,10}$ Other investigators reported that it possess high flexural strength, fracture toughness (Hulbert SF et al; 1972) ${ }^{11}$, radiopaque, biocompatible and with physical properties similar to steel (Ichikawa Y et al; 1992). ${ }^{12}$ The disadvantages include lower fracture resistance than metal posts, difficult retrieval of the fractured post within the root canal, and poor resin-bonding capabilities of the post to radicular dentin (Rovatti L et al; 1998, Cohen BI et al; 2000). ${ }^{10,13}$

The clinician must judge every situation on individual basis and select a procedure that fulfills the needs of the case while minimizing stress and maximizing retention.

\section{CONCLUSION:}

In this case report, a minimally invasive technique of restoration of grossly decayed central incisor with Richmond crown was used. Thus each clinical situation should be evaluated on an individual basis and accordingly treatment plan should be formulated.

\section{FINANCIAL SUPPORT AND SPONSORSHIP}

Nil

\section{CONFLICT OF INTEREST:}

There are no conflicts of interest.

\section{REFERENCES:}

1. The Glossary of Prosthodontic Terms. J Prosthet Dent 2005; 94:10-92

2. Smith CT, Schuman N. Prefabricated post and - core systems: an overview. Compend Contin Educ Dent. 1998;19:1013 -1020

3. Hudis SI, Goldstein GR. Restoration of

Volume No: 8, Issue No: 2 
Yusuf et al: Rehabilitation of fractured Central Incisor with Richmond Crown

endodontically treated teeth: a review of the literature. J Prosthet Dent. 1986; 55:33-38.

4. Fernandes AS, DessaiGS. Factors affecting the fracture resistance of post-core reconstructed teeth: a review. Int $\mathrm{J}$ Prosthodont 2001 Jul-Aug; 14(4):355-63.

5. Rupika Gogna, S Jagadish, K Shashikala, and BS Keshava Prasad. Restoration of badly broken, endodontically treated posterior teeth. J Conserv Dent 2009 Jul-Sep; 12(3): 123-128.

6. Mishra P, Mantri SS, Deogade S, Gupta P. Richmond crown: A lost state of art. Int J Dent Health Sci 2015;2:448-53.

7. Smith CT, Schuman NJ, Wasson W. Biomechanical criteria for evaluating prefabricated post-and-core systems: a guide for the restorative dentist. Quintessence Int 1998;29:305-312.

8. Freedman G. The carbon fibre post: metalfree, post-endodontic rehabilitation. Oral Health 1996;86:23-30.

9. Meyenberg KH, Lüthy H, Schärer P. Zirconia posts: a new all-ceramic concept for nonvital abutment teeth. J Esthet Dent 1995;7(2):7380.

10. Rovatti L, Cavalleri G, Dallari A. A new matrix in esthetic posterior restorations. Compend Contin Educ Dent 1998;19(3):332,334, 6.

11. Hulbert SF, Morrison SJ, Klawitter JJ. Tissue reaction to three ceramics of porous and nonporous structure. J Biomed Mater Res 1972;6:347-374.

12. Ichikawa Y, Akagawa Y, Nikai H, Tsuru H. Tissue compatibility and stability of a new zirconia ceramic in vivo. J Prosthet Dent 1992;68 (2):322-326.

13. Cohen BI, Pagnillo MK, Newman I, Musikant BL, Deutsch AS. Retention of a core material supported by three post head designs. J Prosthet Dent 2000;83(6):624 